\title{
A REMARK ON SCHUR-CONVEXITY OF THE MEAN OF A CONVEX FUNCTION
}

\section{VERA ČULJAK}

Abstract. In this note the new result and some remarks have been made about proving convexity and Schur-convexity of the mean of a convex function $L:[0,1] \rightarrow \mathbb{R}$ associated with the HermitHadamard inequality which is considered in literature [4] and [5]:

$$
L(t):=\frac{1}{2(b-a)} \int_{a}^{b}[f(t a+(1-t) x)+f(t b+(1-t) x)] d x,
$$

where $f: I \subseteq \mathbb{R} \rightarrow \mathbb{R}$ and $a, b \in I, a<b$.

Mathematics subject classification (2010): 26D15,26D99.

Keywords and phrases: convex functions; Schur-convex function; integral arithmetic means.

\section{REFERENCES}

[1] S. S. Dragomir And C. E. M. Pearce, Selected Topics on Hermite-Hadamard Inequalities and Applications, RGMIA Monographs, Victoria University, http://rgmia.vu.edu.au/monographs.

[2] S. S. Dragomir, D. M. MilošEvić And J. SÁndor, On some refinements of Hadamard's inequalities and applications, Univ. Belgrad, Publ. Elek. Fak. Sci. Math., 4 (1993), 21-24.

[3] N. Elezović AND J. PeČARIĆ, A note on Schur-convex functions, Rocky Mountain J. of Mathematics 30, 3 (2000), 853-856.

[4] Huan-NAn ShI, Schur-convex functions related to Hadamard-type inequalities, Journal of Mathematical Inequalities 1, 1 (2007), 127-136.

[5] Huan-Nan Shi, Da-Mao Li and Chun Gu, The Schur-convexity of the mean of a convex function, Applied Mathematics Letter 22, 6 (2009), 932-937.

[6] A.W.Marshall AND I. Olkin, Inequalities: Theory of Majorization and Its Applications, Academic Press, New York

[7] M. Merkle, Convexity, Schur-convexity and bounds for the gamma function involving the digamma function, Rocky Mountain J. Math. 28, 3 (1998), 1053-1066.

[8] J. E. PeČarić, F. Proschan, And Y. L.Tong, Convex functions, partial orderings, and statistical applications, Academic Press, New York.

[9] G.S.YAng AND M.C. Hong, A note on Hadamard's inequality, Tamkang Journal of Mathematics 28, 1 (1997), 33-37. 